\title{
Livestock production performance in India
}

\author{
- RAMJILAL CHOUDHARY, V.J. RATHOD AND V.O. BONDHARE
}

See end of the paper for authors' affiliations

Correspondence to :

V.J. RATHOD

Department of

Agricultural Economics and Statistics, College of

Agriculture, Dr. Panjabrao Deshmukh Krishi

Vidyapeeth, AKOLA (M.S.) INDIA

Paper History:

Received : 23.04.2015;

Revised : 14.06.2015;

Accepted : 13.07.2015
Abstract : Livestock are domesticated animals raised in an agricultural setting to produce commodities such as food, fibre and labour. This article does not discuss poultry or farmed fish, although these, especially poultry, are commonly included within the meaning of "livestock". The objectives of the study was to examine the performance of livestock sector, to identify the remedies to overcome the production loss, to assess the quantum of livestock Population in India and to assess the growth in Production of Milk, Eggs, Meat and Wool in India. The précised secondary data of livestock products; i.e., milk, eggs, meat and wool and their population is collected from the website www.india.stat.com and www.agricoop.nic.in (Department of agriculture and co-operation, New Delhi). Compound Annual Growth Rates (CAGR) was estimated to examine the growth of various livestock products. Data for the study of production of Milk, Eggs, Meat and Wool were collected from the secondary sources for the period 1991-92 to 2010-11 and livestock population in India for period of time interval of 10 years from 1951 to 2011. The production data of milk, eggs, meat and wool pertains to a period of 20 years, i.e., from 1991-92 to 2010-11. The sub-periods framed were as below: Period-I: 1991-92 to 2000-01 (10 years) and Period-II: 2001-02 to 2010-11 (10 years) Overall: 1991-92 to 2010-11 (20 years). The study revealed that the production of milk, meat, eggs, and wool has been increased in its quantum and compound growth rates are also significant. The total livestock population was highest in period of 1981.The population of poultry was highest in year 2001. The maximum growth was observed in case of meat with CGR of 12.16 per cent at period-II. The highest production growth rate of milk was observed in period-II. Eggs production is dominating in overall period while wool production dominating in periodI. There was highest variation in production of meat produce. There is need to increase the production of livestock produce. There is need to strengthening Infrastructure for Quality and Clean Milk Production. There is need to maintain hygienic condition in goat/sheep farm. Government should give subsidies on poultry business for eggs production

KeY Words : Livestock, Population, Compound growth rate, Production

How To Cite This PAper : Choudhary, Ramjilal, Rathod, V.J. and Bondhare, V.O. (2015). Livestock production performance in India. Internat. Res. J. Agric. Eco. \& Stat., 6 (2) : 267-272. 